Article

\title{
Extraction Optimization, Structural Characterization, and Antioxidant Activities of Polysaccharides from Cassia Seed (Cassia obtusifolia)
}

\author{
Ding-Tao Wu ${ }^{\dagger} *\left(\mathbb{D}\right.$, Wen Liu $^{\dagger}$, Qiao-Hong Han, Ping Wang, Xian-Rong Xiang, Ye Ding, Li Zhao, \\ Qing Zhang, Su-Qing Li and Wen Qin * \\ Institute of Food Processing and Safety, College of Food Science, Sichuan Agricultural University, \\ Ya'an 625014, China \\ * Correspondence: DT_Wu@sicau.edu.cn (D.-T.W.); Qinwen@sicau.edu.cn (W.Q.); \\ Tel./Fax: +86-0835-2883219 (W.Q.) \\ + These authors contributed equally to this work.
}

Received: 18 June 2019; Accepted: 31 July 2019; Published: 2 August 2019

check for updates

\begin{abstract}
In order to explore Cassia seed polysaccharides (CSPs) as natural antioxidants for application in the functional-food industry, microwave-assisted extraction (MAE) was optimized for the extraction of CSPs by using a response surface methodology. Furthermore, the chemical structures and antioxidant activities of CSPs extracted by MAE and hot water extraction were investigated and compared. The maximum extraction yield of CSPs extracted by MAE $(8.02 \pm 0.19 \%)$ was obtained at the optimized extraction parameters as follows: microwave power $(415 \mathrm{~W})$, extraction time $(7.0 \mathrm{~min})$, and ratio of water to raw material $(51 \mathrm{~mL} / \mathrm{g})$. Additionally, the contents of the uronic acids, molecular weight, ratio of constituent monosaccharides, intrinsic viscosities, and degrees of esterification of CSPs were significantly affected by the MAE method. Moreover, CSPs exhibited remarkable 2,2' -azino-bis(3-ethylbenzothiazoline-6-sulfonic acid) ABTS, 2,2-diphenyl-1-(2,4,6-trinitrophenyl) hydrazyl DPPH, nitric oxide, and hydroxyl radical scavenging activities as well as reducing power. The high antioxidant activities observed in CSPs extracted by MAE could be partially attributed to its low molecular weights and high content of unmethylated galacturonic acid. Results indicate that the MAE method could be an efficient technique for the extraction of CSPs with high antioxidant activity, and CSPs could be further explored as functional food ingredients.
\end{abstract}

Keywords: Cassia obtusifolia; polysaccharides; microwave-assisted extraction; chemical structure; antioxidant activity

\section{Introduction}

Oxidative stress is usually caused by reactive oxygen species (ROSs) produced during physiologic events [1]. It is well known that some of these ROSs play positive roles in vivo [2]. However, an excessive amount of ROSs can damage cellular components such as lipids, proteins, and DNA when the innate defense in the human body is not enough for severe oxidative stress, a variety of diseases will happen including cancer, aging, and other diseases [3-5]. Generally, antioxidants play important roles in the protection of living organisms [6]. Many antioxidants have been found to be very important in reducing oxidation damage in recent years, but many synthetic antioxidants have toxicological reports [7]. Hence, the search for low toxicity or nontoxic natural antioxidants from plants such as plant derived polysaccharides has become a research hotspot [8].

Cassia obtusifolia L. is a plant of the Leguminosae family, which is a small to medium size tree that is native to tropical and Central America and West India, and widespread in Brazil, a tropical 
country [9,10]. The dry and ripe seed of Cassia is well known as 'Jue Ming Zi' in Chinese [11]. Previous studies have indicated that the Cassia seed exhibits health beneficial effects [12] such as lowering blood glucose level [12], antiallergic activity [13], and antioxidant activity, which is the effect of most concern [14,15]. Phenolic compounds in ethanol extracts of Cassia seed have been identified as natural antioxidants in Cassia seed [12,14,15]. In addition, polysaccharides are also considered to be the main bioactive components in Cassia seed [11,16-19], and possess multiple bioactivities such as remarkable antioxidant activity [2], immunomodulatory activity [11], $\alpha$-amylase inhibitory effect [16], and anti-tumor activity [19]. Therefore, polysaccharides from the Cassia seed can be further explored as functional food ingredients for application in the functional-food industry.

In general, different extraction methods significantly influence the yields, physicochemical characteristics, and bioactivities of polysaccharides extracted from natural resources [20-22]. To extract the polysaccharides from plants, the traditional hot water extraction (HWE) is commonly used. Indeed, the HWE method has been optimized for the extraction of polysaccharides from Cassia seed, and the maximum extraction yield is obtained under the optimal conditions as follows: extraction temperature $\left(80^{\circ} \mathrm{C}\right)$, extraction time $(3.5 \mathrm{~h})$, and ratio of water to raw material $(30 \mathrm{~mL} / \mathrm{g})$ [2]. The HWE method has some shortcomings of a longer extraction time and lower extraction efficiency when compared with other new techniques [2,23-25]. Additionally, some physical methods can be used to facilitate the extraction process. Microwave-assisted extraction (MAE) has several advantages during extraction such as a low operation time, high efficiency, and high extraction yield [26-28]. Indeed, several studies have demonstrated that natural polysaccharides extracted by MAE exhibit much higher antioxidant activity than that of HWE $[21,29,30]$. The microwave-assisted aqueous two-phase extraction has been utilized to extract the polysaccharides from Cassia seed [31], and the maximum extraction yield is obtained under the optimal conditions as follows: the composition of $25.4 \%$ ethanol and $22.0 \%$ ammonium sulfate for the aqueous two-phase system, temperature of $80^{\circ} \mathrm{C}, 20 \mathrm{~min}$ extraction time, and a 60:1 solvent-to-material ratio. However, the composition and extraction time of this procedure is relatively complex and long. Furthermore, to the best of our knowledge, the microwave-assisted extraction of polysaccharides from Cassia seed have seldom been optimized, and the effects of MAE and HWE methods on the chemical characteristics and antioxidant activities of CSPs have seldom been compared. Therefore, in order to explore CSPs as functional food ingredients and natural antioxidants for industrial applications, and to evaluate the effects of the MAE method on the physicochemical characteristics and antioxidant activities of CSPs, the MAE method was first optimized for the extraction of CSPs by using the response surface methodology, and then the chemical structures and antioxidant activities of CSPs obtained by two kinds of extraction methods (MAE and HWE) were compared.

\section{Results and Discussions}

\subsection{Optimization of Microwave-Assisted Extraction of Polysaccharides from Cassia Seed}

The microwave power, microwave extraction time, and ratio of water to raw material are significant parameters that affect the extraction yield of polysaccharides [21]. The effects of these parameters on the yields of CSPs are shown in Figure 1. Briefly, the yields of CSPs were positively related to an increase of microwave power from 240 to $400 \mathrm{~W}$, and then decreased (Figure 1A). This might be because an increase in microwave power could promote heat generation in the mixture and enhance the extraction yields. However, a too high microwave power could cause the degradation of polysaccharides [32]. In addition, the yields of CSPs increased while the ratio of water to raw material increased from 30 to $50 \mathrm{~mL} / \mathrm{g}$, and reached the highest yield at $50 \mathrm{~mL} / \mathrm{g}$ (Figure 1B). However, the yield of CSPs decreased significantly while the ratio of water to raw material continued to increase, which might be due to a higher ratio of water to raw material, possibly leading to a lower density and viscosity, thereby facilitating the dilution of polysaccharides in the solvent [33]. Furthermore, the yields of CSPs increased while the extraction time increased from 2 to $6 \mathrm{~min}$, and the highest extraction yield was reached at 6 min (Figure 1C). The yield decreased when the extraction time increased continuously. This could 
imply that an increased extraction time can make the extraction procession become easier and quicker, but the degradation of polysaccharides might be caused by a too long extraction time $[34,35]$. Finally, the optimal extraction conditions were determined to be $400 \mathrm{~W}, 50 \mathrm{~mL} / \mathrm{g}$, and $6 \mathrm{~min}$. Based on the results above, a Box-Behnken experimental design (BBD) was further utilized to optimize the MAE conditions. Table 1 summarizes the BBD matrix and the experimental data for the MAE method. A final second-order polynomial equation in terms of coded values was obtained by applying multiple regression analysis:

$$
\begin{aligned}
\mathrm{Y}=+7.98+ & 0.26 \mathrm{X}_{1}+0.13 \mathrm{X}_{2}+0.33 \mathrm{X}_{3}+0.076 \mathrm{X}_{1} \mathrm{X}_{2}-0.15 \mathrm{X}_{1} \mathrm{X}_{3} \\
& +0.23 \mathrm{X}_{2} \mathrm{X}_{3}-0.61 \mathrm{X}_{1}^{2}-0.74 \mathrm{X}_{2}^{2}-0.60 \mathrm{X}_{3}^{2}
\end{aligned}
$$

where $Y$ represents the extraction yield, and $X_{1}, X_{2}$, and $X_{3}$ are the microwave power, ratio of water to raw material, and extraction time, respectively.
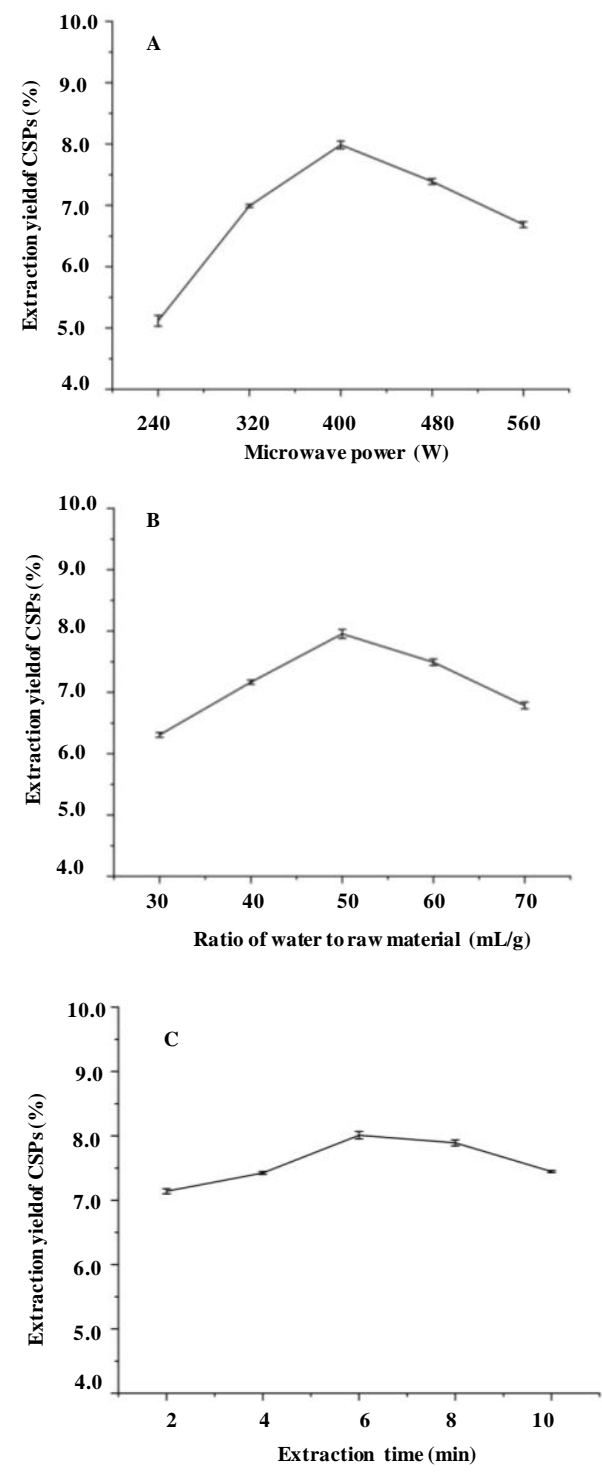

Figure 1. Effect of different microwave power (A), ratio of water to raw material (B), extraction time (C) on the extraction yields of CSPs. 
Table 1. Box-Behnken design with independent variables and observed values for microwave-assisted extraction (MAE).

\begin{tabular}{ccccc}
\hline \multirow{2}{*}{ Variable } & \multicolumn{3}{c}{ Levels of Independent Factors } & \multirow{2}{*}{ Extraction Yields \% } \\
\cline { 2 - 3 } & $\mathbf{X}_{\mathbf{1}} \mathbf{( W )}$ & $\mathbf{X}_{\mathbf{2}} \mathbf{( \mathbf { m L } / \mathbf { g } )}$ & $\mathbf{X}_{\mathbf{3}} \mathbf{( \mathbf { m i n } )}$ & \\
\hline $\mathbf{1}$ & $-1(320)$ & $0(50)$ & $-1(4)$ & 6.08 \\
$\mathbf{2}$ & $0(400)$ & $0(50)$ & $0(6)$ & 7.98 \\
$\mathbf{3}$ & $0(400)$ & $0(50)$ & $0(6)$ & 7.89 \\
$\mathbf{4}$ & $1(480)$ & $0(50)$ & $1(8)$ & 7.14 \\
$\mathbf{5}$ & $0(400)$ & $0(50)$ & $0(6)$ & 8.01 \\
$\mathbf{6}$ & $1(480)$ & $0(50)$ & - & 6.83 \\
$\mathbf{7}$ & $0(400)$ & $1(60)$ & $1(8)$ & 7.34 \\
$\mathbf{8}$ & $-1(320)$ & $0(50)$ & $1(8)$ & 7.01 \\
$\mathbf{9}$ & $-1(320)$ & $-1(40)$ & $0(6)$ & 6.28 \\
$\mathbf{1 0}$ & $1(480)$ & $1(60)$ & $0(6)$ & 7.12 \\
$\mathbf{1 1}$ & $1(480)$ & $-1(40)$ & $0(6)$ & 6.72 \\
$\mathbf{1 2}$ & $0(400)$ & $0(50)$ & $0(6)$ & 7.96 \\
$\mathbf{1 3}$ & $-1(320)$ & $1(60)$ & $0(6)$ & 6.37 \\
$\mathbf{1 4}$ & $0(400)$ & $0(50)$ & $0(6)$ & 8.04 \\
$\mathbf{1 5}$ & $0(400)$ & $-1(40)$ & $-1(4)$ & 6.38 \\
$\mathbf{1 6}$ & $0(400)$ & $1(60)$ & $-1(4)$ & 6.19 \\
$\mathbf{1 7}$ & $0(400)$ & $-1(40)$ & $1(8)$ & 6.60 \\
\hline
\end{tabular}

$\mathbf{X}_{1}$, microwave power $(\mathrm{W}) ; \mathbf{X}_{2}$, ratio of water to raw material $(\mathrm{mL} / \mathrm{g}) ; \mathbf{X}_{3}$, extraction time (min).

In the BBD analysis, the significance of the model equation was checked by the $F$-values and $p$-value [21]. As shown in Table 2, the fitness of the model was highly significant based on the high $F$-value (227.16) and the very low $p$-value $(p<0.0001)$ [20]. Furthermore, the lack of fit was not significant based on the lack of fit $F$-value of 1.67 and $p$-value of $0.3099(p>0.05)$. Results indicated that the model equation was adequate for predicting the yield of CSPs [30]. Furthermore, this model had good precision and reliability according to the low value of the coefficient variation (C.V., $0.88 \%$ ) and the high value of the adeq. precision (40.84) [23]. Furthermore, the $R^{2}$ and $R_{a d j}{ }^{2}$ were 0.9966 and 0.9922 , respectively, which indicated a high degree of correlation between the observed and predicted values [32]. In addition, the linear coefficients $\left(X_{1}, X_{2}, X_{3}\right)$, interaction coefficients $\left(X_{1} X_{2}, X_{1} X_{3}\right.$, and $\left.\mathrm{X}_{2} \mathrm{X}_{3}\right)$, and quadratic term coefficients $\left(\mathrm{X}_{1}{ }^{2}, \mathrm{X}_{2}{ }^{2}\right.$, and $\left.\mathrm{X}_{3}{ }^{2}\right)$ of the model equation were significant $(p<0.05)$, respectively.

Table 2. Analysis of the variance of the regression equation and coefficients of microwaveassisted extraction.

\begin{tabular}{cccccc}
\hline \multirow{2}{*}{ Source ${ }^{\mathbf{a}}$} & \multicolumn{5}{c}{ Microwave-Assisted Extraction } \\
\cline { 2 - 6 } & Sum of Square & $\mathbf{d f}^{\mathbf{b}}$ & Mean Square & $\boldsymbol{F}$-Value & $p$-Value ${ }^{\mathbf{c}}$ \\
\hline Model & 7.90 & 9 & 0.88 & 227.16 & $<0.0001^{* *}$ \\
$\mathbf{X}_{\mathbf{1}}$ & 0.54 & 1 & 0.54 & 139.36 & $<0.0001^{* *}$ \\
$\mathbf{X}_{\mathbf{2}}$ & 0.14 & 1 & 0.14 & 35.42 & $0.0006^{* *}$ \\
$\mathbf{X}_{\mathbf{3}}$ & 0.85 & 1 & 0.85 & 219.73 & $<0.0001^{* *}$ \\
$\mathbf{X}_{\mathbf{1}} \mathbf{X}_{\mathbf{2}}$ & 0.023 & 1 & 0.023 & 6.02 & $0.0439^{*}$ \\
$\mathbf{X}_{\mathbf{1}} \mathbf{X}_{\mathbf{3}}$ & 0.092 & 1 & 0.092 & 23.88 & $0.0018^{* *}$ \\
$\mathbf{X}_{\mathbf{2}} \mathbf{X}_{\mathbf{3}}$ & 0.22 & 1 & 0.22 & 56.26 & $0.0001^{* *}$ \\
$\mathbf{X}_{\mathbf{1}}{ }^{*}$ & 1.55 & 1 & 1.55 & 401.81 & $<0.0001^{* *}$ \\
$\mathbf{X}_{\mathbf{2}}{ }^{2}$ & 2.33 & 1 & 2.33 & 603.76 & $<0.0001^{* *}$ \\
$\mathbf{X}_{\mathbf{3}}{ }^{2}$ & 1.53 & 1 & 1.53 & 395.76 & $<0.0001^{* *}$ \\
Residual Error & 0.027 & 7 & $3.864 \times 10^{-3}$ & & \\
Lack of Fit & 0.015 & 3 & $5.009 \times 10^{-3}$ & 1.67 & 0.3099 \\
Pure Error & 0.012 & 4 & $3.006 \times 10^{-3}$ & & \\
Correlation Total & 7.93 & 16 & & & \\
\hline$R^{2}=0.9966^{2}$ & & & & & \\
\hline
\end{tabular}

$R^{2}=0.9966, R_{\text {adj }}^{2}=0.9922$, coefficient of variation $=0.88 \%$, adeq. precision $=40.84 ;{ }^{\text {a }} \mathbf{X}_{\mathbf{1}}$, microwave power $(\mathrm{W}) ; \mathbf{X}_{2}$, ratio of water to raw material $(\mathrm{mL} / \mathrm{g}) ; \mathbf{X}_{3}$, microwave extraction time $(\mathrm{min}){ }^{\mathrm{b}}{ }^{\mathrm{df}}$, the degree of freedom; $c *$, Significantly different $(p<0.05),{ }^{* *}$ Extremely significantly different $(p<0.01)$. 
The predicted models were presented in three-dimensional (3D) response surface plots and two-dimensional contour plots as shown in Figure 2. Generally, for 2D contour plots, an elliptical contour plot indicates the significant interactions between the variables [35]. And a further understanding was given by $3 \mathrm{D}$ response surface plots. In this study, it was clear that the interaction between the microwave power and the ratio of water to raw material (Figure 2B), the microwave power and the extraction time (Figure 2D), and the ratio of water to raw material and the extraction time (Figure 2F) were significant, respectively. Furthermore, the model predicted that the maximum yield $(8.05 \%)$ could be obtained by the optimal extraction conditions: the microwave power of $415.05 \mathrm{~W}$; the ratio of water to raw material, $51.41 \mathrm{~mL} / \mathrm{g}$; and the extraction time of $6.55 \mathrm{~min}$. However, considering the practical operability, the operating conditions were: a power of $415 \mathrm{~W}$; the ratio of $51 \mathrm{~mL} / \mathrm{g}$; and the time of $7.0 \mathrm{~min}$. The actual yield of $8.02 \pm 0.19 \%(\mathrm{n}=3)$ was obtained, which is similar to the predicted value. The results showed that the model for MAE was accurate and adequate in the present study. Furthermore, the MAE method optimized in the present study possessed a higher extraction yield $(8.05 \%)$ and extremely shorter extraction time $(7.0 \mathrm{~min})$ than that of the previously optimized HWE method (extraction yield of $5.46 \%$ with the extraction time of $210.0 \mathrm{~min}$ ) [2]. Indeed, the extraction time of the optimized MAE method was also shorter than that of the previously reported microwave-assisted aqueous two-phase extraction method (extraction time of $20.0 \mathrm{~min}$ ) [31].
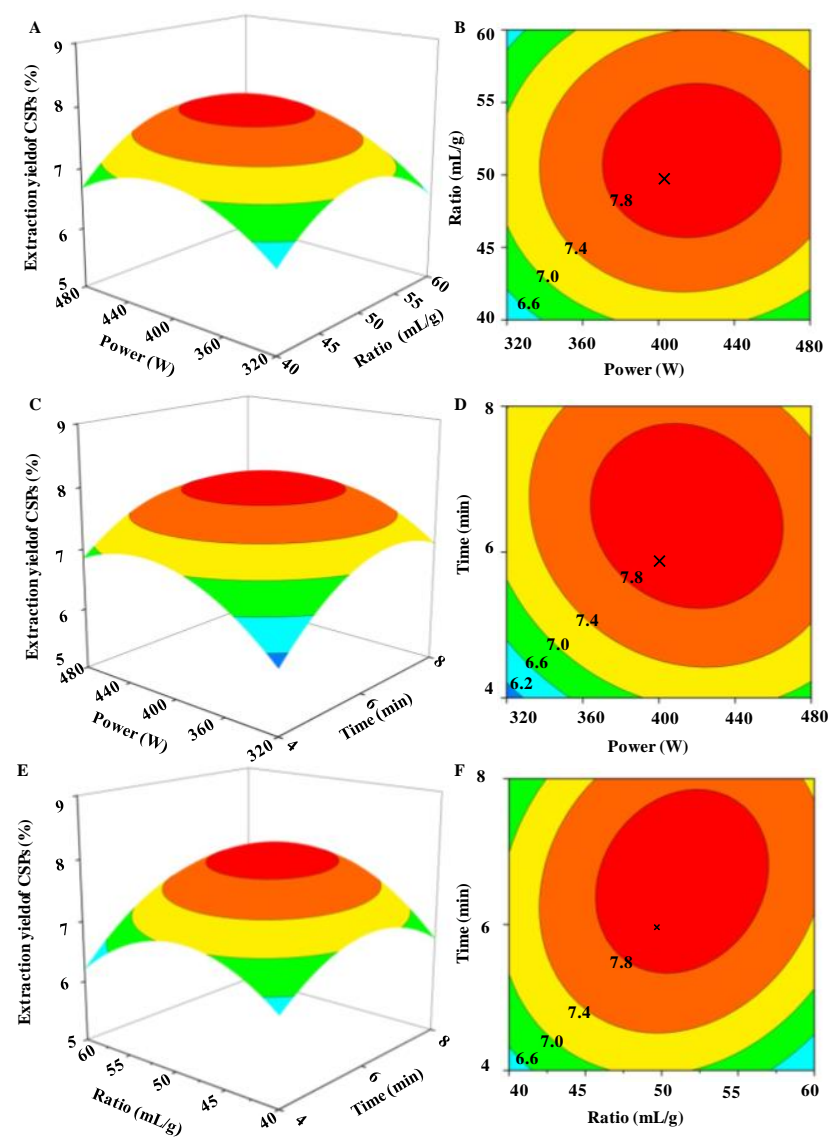

Figure 2. Three-dimensional response surface (left) and two-dimensional contour (right) plots of microwave-assisted extraction. (A,B) microwave power and ratio of water to raw material; $(\mathbf{C}, \mathbf{D})$ microwave power and microwave extraction time; $(\mathbf{E}, \mathbf{F})$ ratio of water to raw material and microwave extraction time, respectively. 
2.2. Comparison of Physicochemical Characteristics of CSPs from Cassia Seed Extracted by HWE (CSP-W) and $M A E(C S P-M)$

\subsubsection{Chemical Compositions of CSP-W and CSP-M}

The extraction yields of CSPs extracted by HWE (CSP-W) and MAE (CSP-M) were determined as $8.17 \pm 0.33 \%$ and $8.02 \pm 0.19 \%$, respectively, which were a little higher than that of the previous study [11]. Results showed that the extraction yields of CSPs under the optimal extraction conditions of MAE and HWE were almost the same, and the advantage of MAE mainly regarded the reduced extraction time. Therefore, considering the time and temperature (Table 3), MAE could be better than HWE. High carbohydrate contents and low protein contents were observed in CSP-W $(80.76 \pm 1.19 \%$ and $4.80 \pm 0.03 \%)$ and CSP-M $(85.38 \pm 1.04 \%$ and $5.50 \pm 0.12 \%)$, respectively. In addition, the total uronic acids content in CSP-W $(20.14 \pm 0.59 \%)$ was significantly $(p<0.05)$ higher than that of CSP-M $(18.44 \pm 0.67 \%)$. The results suggest that different extraction methods had significant effects on the contents of uronic acids in the polysaccharides [29]. Indeed, the low content of uronic acids in CSP-M might be due to the degradation of CSPs under microwave irradiation [21].

Table 3. Extraction conditions and chemical composition of CSP-W and CSP-M.

\begin{tabular}{ccc}
\hline Chemical Composition & \multicolumn{2}{c}{ Samples } \\
\cline { 2 - 3 } & CSP-W & CSP-M \\
\hline Extraction Yields (\%) & $8.17 \pm 0.33^{\mathrm{a}}$ & $8.02 \pm 0.19^{\mathrm{a}}$ \\
Extraction Time (min) & 240 & 7 \\
Extraction Temperature ( $\left.{ }^{\circ} \mathrm{C}\right)$ & 90 & 85 \\
Total Polysaccharides (\%) & $80.76 \pm 1.19^{\mathrm{b}}$ & $85.38 \pm 1.04^{\mathrm{a}}$ \\
Total Uronic Acids (\%) & $20.14 \pm 0.59^{\mathrm{a}}$ & $18.44 \pm 0.67^{\mathrm{b}}$ \\
Degree of Esterification (\%) & $11.88 \pm 0.67^{\mathrm{a}}$ & $4.70 \pm 0.25^{\mathrm{b}}$ \\
Proteins (\%) & $4.80 \pm 0.03^{\mathrm{b}}$ & $5.50 \pm 0.12^{\mathrm{a}}$ \\
\hline
\end{tabular}

CSP-W, Cassia seed polysaccharides extracted by hot water extraction; CSP-M, Cassia seed polysaccharides extracted by microwave-assisted extraction; Values represent mean \pm standard deviation, and superscripts a and $\mathrm{b}$ differ significantly $(p<0.05)$ among CSP-W and CSP-M; Statistical significances were carried out by independent-sample $t$-test.

\subsubsection{Molecular Weights, Intrinsic Viscosities, and Constituent Monosaccharides of CSP-W and CSP-M}

Generally, the activities of polysaccharides are correlated to their molecular weights $\left(M_{w}\right)$ and constituent monosaccharides [36]. When their $M_{w}$ decrease, some polysaccharides might show decreased intrinsic viscosity and enhanced bioactivities [23,37]. Therefore, these chemical characteristics of CSPs extracted by HWE and WAE were compared. Figure 3 shows the HPSEC-RID chromatograms of the CSPs. Three fractions (Figure 3, fraction 1, 2, and 3) were detected in CSP-W and CSP-M. As shown in Table 4, the $M_{w}$ of three polysaccharide fractions (fraction 1, fraction 2, and fraction 3) in CSP-W were determined to be $1.337 \times 10^{6} \mathrm{Da}, 9.838 \times 10^{4} \mathrm{Da}$, and $2.514 \times 10^{4} \mathrm{Da}$, respectively, and the $M_{w}$ of three fractions (fraction 1, fraction 2, and fraction 3) in CSP-M were determined to be $1.091 \times 10^{6} \mathrm{Da}, 1.476 \times 10^{5} \mathrm{Da}$, and $3.615 \times 10^{4} \mathrm{Da}$, respectively. Moreover, fraction 1 and fraction 2 were the dominant peaks, which were a little higher than that of the polysaccharides isolated from the seeds of Cassia $[11,38,39]$. The results indicated that the high $M_{w}$ fraction (fraction 1) of CSP-W were degraded and converted into lower $M_{w}$ fractions (fraction 2) during microwave-assisted extraction (Figure 3). Studies have indicated that the $M_{w}$ of polysaccharides extracted by MAE are lower than that of conventional HWE [23,29]. Meanwhile, the polydispersities of different fractions in CSP-W were $1.562,1.423$, and 1.255, respectively, and that of CSP-M were 1.327, 1.234, and 1.170, respectively. In addition, the activities of polysaccharides such as anti-inflammatory and antioxidant activities are influenced by the intrinsic viscosity [ $\eta$ ] [40]. As shown in Table 4, the [ $\eta$ ] of CSP-W and CSP-M were observed as $2.81 \pm 0.05 \mathrm{dL} / \mathrm{g}$ and $2.70 \pm 0.04 \mathrm{dL} / \mathrm{g}$, respectively, which is higher than the intrinsic viscosities of Cassia seed polysaccharides in a previous study [39]. The [ $\eta$ ] of CSP-M was significantly lower than that of CSP-W, suggesting the intrinsic viscosity can be decreased under the microwave treatment [40]. 

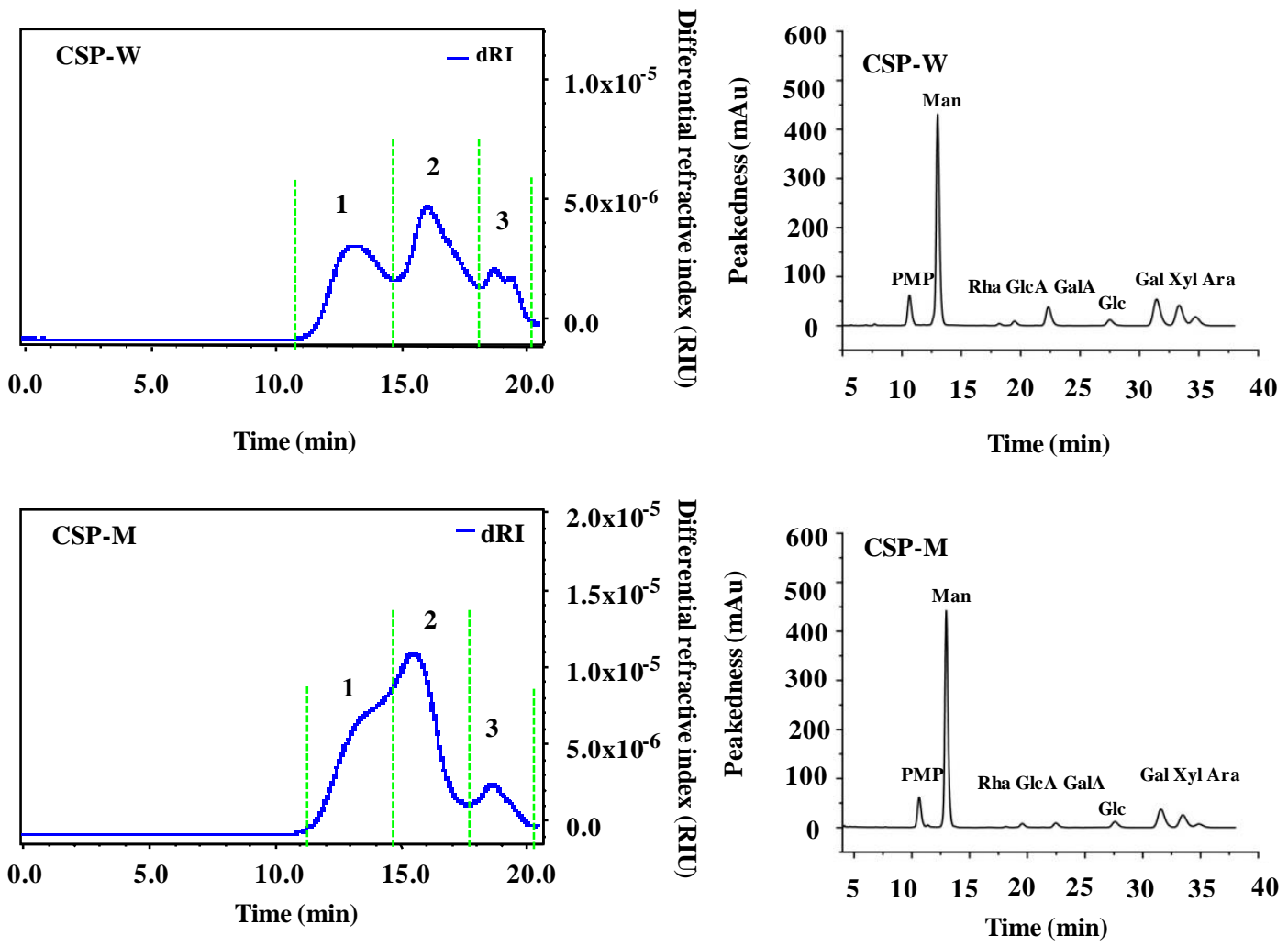

Figure 3. High performance size exclusion chromatograms (left) and high performance liquid chromatography profiles (right) of CSP-W and CSP-M. CSP-W, Cassia seed polysaccharides extracted by hot water extraction; CSP-M, Cassia seed polysaccharides extracted by microwave-assisted extraction; PMP, 1-phenyl-3-methyl-5-pyrazolone; Man, mannose; Rha, rhamnose; GlcA, glucuronic acid; GalA, galacturonic acid; Glc, glucose; Gal, galactose; Xyl, xylose; Ara, arabinose.

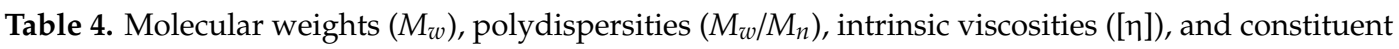
monosaccharides of CSP-W and CSP-M.

\begin{tabular}{|c|c|c|}
\hline & \multicolumn{2}{|c|}{ Samples } \\
\hline & CSP-W & CSP-M \\
\hline \multicolumn{3}{|l|}{$M_{w} \times 10^{4}(\mathrm{Da}$, Error $)$} \\
\hline Fraction 1 & $133.7( \pm 1.55 \%)^{\mathrm{a}}$ & $109.1( \pm 1.09 \%)^{b}$ \\
\hline Fraction 2 & $9.838( \pm 1.88 \%)^{b}$ & $14.760( \pm 2.33 \%)^{\mathrm{a}}$ \\
\hline Fraction 3 & $2.514( \pm 3.66 \%)^{b}$ & $3.615( \pm 4.16 \%)^{\mathrm{a}}$ \\
\hline$M_{w} / M_{n}$ & & \\
\hline Fraction 1 & 1.562 & 1.327 \\
\hline Fraction 2 & 1.423 & 1.234 \\
\hline Fraction 3 & 1.255 & 1.170 \\
\hline$[\eta](\mathrm{dL} / \mathrm{g})$ & $2.81 \pm 0.05^{\mathrm{a}}$ & $2.70 \pm 0.04^{\mathrm{b}}$ \\
\hline \multicolumn{3}{|c|}{ Monosaccharide Compositions (Molar Ratio) } \\
\hline Mannose & 2.28 & 2.88 \\
\hline Rhamnose & 0.07 & 0.05 \\
\hline Glucuronic Acid & 0.12 & 0.06 \\
\hline Galacturonic Acid & 0.52 & 0.14 \\
\hline Glucose & 0.17 & 0.20 \\
\hline Galactose & 1.00 & 1.00 \\
\hline Xylose & 0.79 & 0.72 \\
\hline Arabinose & 0.29 & 0.13 \\
\hline
\end{tabular}

CSP-W, Cassia seed polysaccharides extracted by hot water extraction; CSP-M, Cassia seed polysaccharides extracted by microwave-assisted extraction; Values represent mean \pm standard deviation, and superscripts a and $\mathrm{b}$ differ significantly $(p<0.05)$ among CSP-W and CSP-M; Statistical significances were carried out by an independent-sample $t$-test. 
Furthermore, Figure 3 also shows the HPLC-UV profiles of CSPs. Similar constituent monosaccharides were measured in CSP-W and CSP-M, which were determined as Man, Rha, GlcA, GalA, Glc, Gal, Xyl, and Ara. The major compositional monosaccharides were similar to some previous studies, suggesting that the CSPs obtained in this study contained pectic polysaccharides [10,11]. As shown in Table 4, the molar ratios of Man, Rha, GlcA, GalA, Glc, Gal, Xyl, and Ara in CSP-W and CSP-M were determined to be 2.28:0.07:0.12:0.52:0.17:1.00:0.79:0.29 and 2.88:0.05:0.06:0.14:0.20:1.00:0.72:0.13, respectively. Results suggest that the microwave assisted extraction had no effect on the types of compositional monosaccharides of CSPs, but affected their molar ratios. Previous studies have indicated that extraction methods can affect the molar ratios of compositional monosaccharides [21,30]. Furthermore, the results suggested that galactomannan (GM), homogalacturonan (HG), glucuronoxylan and arabinogalactan (AG II) might exist in CSPs from Cassia seed extracted by HWE and MAE [10,11,31]. Indeed, previous studies have demonstrated that glucuronoxylan and galactomannans exist in the CSPs $[17,18,39]$.

\subsubsection{Fourier Transform Infrared Spectra and Degree of Esterification of CSP-W and CSP-M}

Fourier transform infrared (FT-IR) spectra between 4000 and $500 \mathrm{~cm}^{-1}$ were obtained for the analysis of organic functional groups in CSP-W and CSP-M, and the results are shown in Figure 4. The similar Fourier transform infrared spectra of CSPs indicated that CSP-W and CSP-M have similar structures. In brief, the absorption at $3404 \mathrm{~cm}^{-1}$ corresponded to the stretching vibration of the hydroxyl group, while the weak peak at $2926 \mathrm{~cm}^{-1}$ corresponded to the stretching vibration of $\mathrm{C}-\mathrm{H}[21,40]$. The absorption bands between $1780 \mathrm{~cm}^{-1}$ and $1710 \mathrm{~cm}^{-1}$ are due to the $\mathrm{C}=\mathrm{O}$ stretching vibration of the esterified groups [38]. Furthermore, the intense peak that appeared at $1635 \mathrm{~cm}^{-1}$ was assigned to the $\mathrm{C}=\mathrm{O}$ asymmetric stretching of $\mathrm{COO}^{-}$, suggesting the existence of uronic acids in CSPs, which was also confirmed by the m-hydroxydiphenyl analysis method and compositional monosaccharide analysis $[2,21,41]$. In addition, the band at $1420 \mathrm{~cm}^{-1}$ was assigned to the $\mathrm{C}-\mathrm{H}$ stretching vibrations or O-H deformation vibrations [2,42,43]. Typical protein bands at $1651 \mathrm{~cm}^{-1}$ and $1555 \mathrm{~cm}^{-1}$ were not detected, which indicated the low amount of proteins in CSPs. Results were similar with the low contents of proteins determined by Bradford's method [42]. Moreover, the band at $814 \mathrm{~cm}^{-1}$ corresponded to $\alpha$-D-galactopyranose [2], which is similar to the constituent monosaccharides of CSPs. Furthermore, the degrees of esterification (DE) of CSPs extracted by HWE and MAE could be obtained by the FT-IR results. Significantly $(p<0.05)$ higher DE values $(11.88 \%)$ were observed in CSP-W, and lower values $(4.70 \%)$ in CSP-M. Previous studies have indicated that the low DE might contribute to the relatively high antioxidant activity [44]. Furthermore, results suggest that the MAE method significantly affected the DE of CSPs, and that the low DE value might be caused by these harsh conditions $[45,46]$.

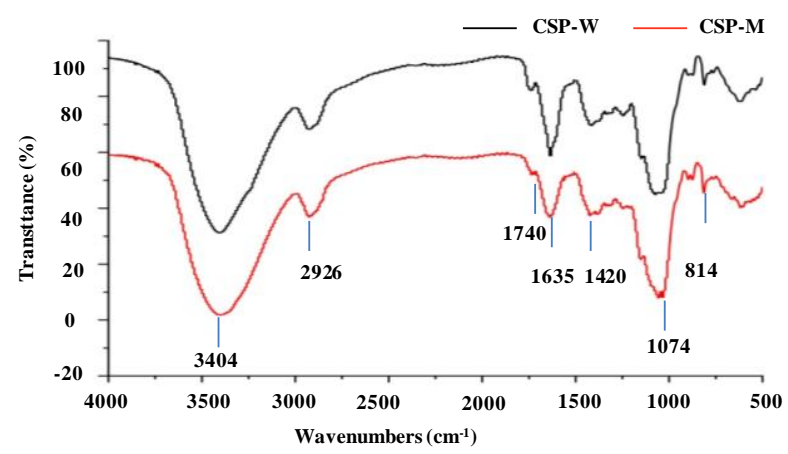

Figure 4. FT-IR spectra of CSP-W and CSP-M. CSP-W, Cassia seed polysaccharides extracted by hot water extraction; CSP-M, Cassia seed polysaccharides extracted by microwave-assisted extraction. 


\subsection{Comparison of Antioxidant Activities of CSPs from Cassia Seed Extracted by HWE and MAE}

Studies have indicated that CSPs from Cassia seed possess remarkable antioxidant activities [2,31]. Therefore, in this study, the in vitro antioxidant activities of CSPs were determined. The ABTS, DPPH, $\mathrm{NO}$, and $\mathrm{OH}$ radical scavenging activities, and reducing powers of CSPs are shown in Figure 5, respectively. CSPs exhibited strong in vitro antioxidant activities and different extraction methods could affect the antioxidant activities of CSPs. Briefly, as shown in Figure 5A, CSP-W and CSP-M had substantial scavenging activities for the ABTS radical cation at all tested concentrations in a dose-dependent manner, and the significantly $(p<0.05)$ higher ABTS radical scavenging activities were observed in CSP-M. The MAE could be a good potential method for the extraction of Cassia seed polysaccharides. Additionally, the $\mathrm{IC}_{50}$ values of the ABTS radical scavenging activities of CSP-W and CSP-M were determined as $3.04 \mathrm{mg} / \mathrm{mL}$ and $2.11 \mathrm{mg} / \mathrm{mL}$, respectively. This shows that CSP-M has a moderate antioxidant activity, even if the $\mathrm{IC}_{50}$ value of CSP-M is higher than BHT (a positive control, $\mathrm{IC}_{50}=0.025 \mathrm{mg} / \mathrm{mL}$ ). Moreover, CSP-M showed higher antioxidant activity than that of other polysaccharides [40,47-49]. As shown in Figure 5B, the DPPH radical scavenging activities of CSPs also exhibited a dose-dependent manner. CSP-M showed significantly $(p<0.05)$ higher DPPH radical scavenging activities than that of CSP-W. Indeed, the IC $_{50}$ values of CSP-W and CSP-M were determined as $5.83 \mathrm{mg} / \mathrm{mL}$ and $4.41 \mathrm{mg} / \mathrm{mL}$, respectively. CSP-M also exhibited stronger DPPH radical scavenging activities than CSP-W, but still lower than the BHT (a positive control, $\mathrm{IC}_{50}=0.41 \mathrm{mg} / \mathrm{mL}$ ). As shown in Figure 5C, CSPs extracted by HWE and MAE also exhibited obvious scavenging activities on NO in a dose-dependent manner. The $\mathrm{IC}_{50}$ values of CSP-W and CSP-M were determined as 3.19 $\mathrm{mg} / \mathrm{mL}$ and $2.10 \mathrm{mg} / \mathrm{mL}$, respectively, which were higher than that of vitamin $\mathrm{C}\left(\mathrm{IC}_{50}=0.23 \mathrm{mg} / \mathrm{mL}\right.$ ). Furthermore, as shown in Figure 5D, CSPs extracted by HWE and MAE also exerted OH scavenging activities. The $\mathrm{IC}_{50}$ values of CSP-W and CSP-M were determined as $4.01 \mathrm{mg} / \mathrm{mL}$ and $3.16 \mathrm{mg} / \mathrm{mL}$, respectively, which confirmed that CSP-M exhibited stronger $\mathrm{OH}$ radical scavenging activities than that of CSP-W. In addition, compared with vitamin C ( $\left.\mathrm{IC}_{50}=0.23 \mathrm{mg} / \mathrm{mL}\right), \mathrm{CSP}-\mathrm{M}$ also exhibited moderate $\mathrm{OH}$ radical scavenging activities.

Moreover, as shown in Figure 5E, a significantly $(p<0.05)$ higher reducing power was also in CSP-M from $1.0 \mathrm{mg} / \mathrm{mL}$ to $5.0 \mathrm{mg} / \mathrm{mL}$, followed by a lower reducing power in CSP-W. Although CSP-M showed a lower reducing power than BHT, while at the concentration of $5.0 \mathrm{mg} / \mathrm{mL}$, its absorbance still reached 0.49 at $700 \mathrm{~nm}$. CSPs could be one of the major contributors toward the antioxidant activities of Cassia seed. In general, the antioxidant activities of polysaccharides are related to their structural features, $M_{w}$, and compositional monosaccharides (especially uronic acids) [21,40,50,51]. The presence of electrophilic groups such as keto or aldehyde in acidic polysaccharides could improve the radical scavenging activities [30]. In this study, the higher antioxidant activities (ABTS, DPPH, $\mathrm{NO}$, and $\mathrm{OH}$ radical scavenging activities, and reducing power) observed in CSP-M might be partially attributed to its lower $M_{w}$ and higher content of unmethylated galacturonic acids [4,23]. However, further purification, structural characterization, and in vitro and in vivo antioxidant activities of CSPs are required to reveal their relationships between structure and bioactivity. 

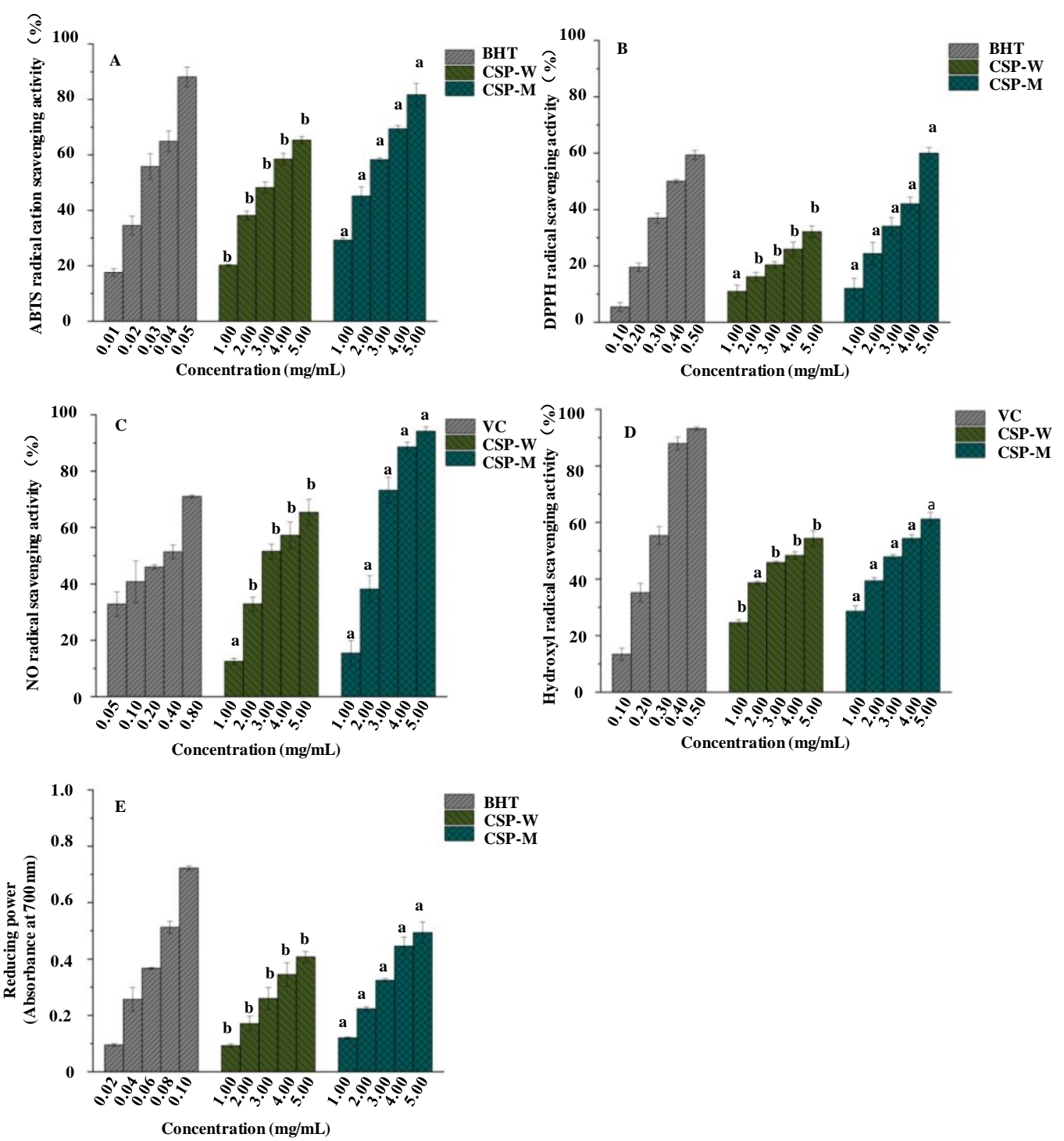

Figure 5. ABTS (A), DPPH (B), nitric oxide (C), and hydroxyl (D) radical scavenging activities, and reducing powers (E) of CSP-W and CSP-M. CSP-W, Cassia seed polysaccharides extracted by hot water extraction; CSP-M, Cassia seed polysaccharides extracted by microwave-assisted extraction; The error bars are standard deviations; significant $(p<0.05)$ differences between CSP-W and CSP-M at the same concentration are shown by data bearing different letters $(a, b)$; statistical significances were carried out by an independent sample $t$-test.

\section{Material and Methods}

\subsection{Samples and Chemicals}

Cassia seeds were obtained from a market in Ya'an, China and dried at a temperature of $45^{\circ} \mathrm{C}$ for two days. Subsequently, the dried Cassia seeds were ground to pass through a 60 mesh sieve and stored at $-20^{\circ} \mathrm{C}$ for further analysis.

Trifluoroacetic acid, rhamnose, glucuronic acid, galacturonic acid, mannose, glucose, galactose, xylose, arabinose, m-hydroxydiphenyl, griess reagent, sodium nitroprusside (SNP), 1-phenyl-3-methyl-5-pyrazolone (PMP), 2,2-diphenyl-1-(2,4,6-trinitrophenyl) hydrazyl (DPPH), 2,2'-azino-bis(3-ethylbenzothiazoline-6-sulfonic acid) (ABTS), hydrogen peroxide, vitamin C, and butylated hydroxytoluene (BHT) were purchased from Sigma-Aldrich (St. Louis, MO, USA). All other reagents and chemicals used were of analytical grade. 


\subsection{Extraction of Polysaccharides from Cassia Seed}

\subsubsection{Hot Water Extraction of CSPs}

Hot water extraction (HWE) was performed based on a previously reported method with minor modifications [52]. Briefly, the Cassia seed powders (1.0 g) were first refluxed with $10 \mathrm{~mL}$ of $80 \%(v / v)$ ethanol at $80^{\circ} \mathrm{C}$ for $2 \mathrm{~h}$ to remove most of the small molecules. Then, the polysaccharides from Cassia seed (CSPs) were extracted twice with $30 \mathrm{~mL}$ of deionized water at $90{ }^{\circ} \mathrm{C}$ for $2 \mathrm{~h}$. Furthermore, four volumes of $95 \%$ ethanol $(v / v)$ were utilized for the precipitation of polysaccharides in the supernatants over night at $4{ }^{\circ} \mathrm{C}$. Finally, the crude polysaccharides extracted from Cassia seed (CSP-W) were freeze dried and stored at $-20^{\circ} \mathrm{C}$ for further analysis.

\subsubsection{Microwave-Assisted Extraction of CSPs}

Microwave-assisted extraction (MAE) was performed based on a previously reported method with some modifications [30]. Both the single-factor experimental design and Box-Behnken experimental design were also applied for the optimization of the MAE conditions. Briefly, the Cassia seed powders $(1.0 \mathrm{~g})$ were first refluxed with $10 \mathrm{~mL}$ of $80 \%(v / v)$ ethanol at $80{ }^{\circ} \mathrm{C}$ for $2 \mathrm{~h}$ to remove most of the small molecules. Then, the extract residue was extracted with deionized water by MAE (MKJ-J1-3, Qingdao Makewave Microwave Applied Technology Co. Ltd., Shandong, China) and the effects of the microwave power $(240,320,400,480$, and $560 \mathrm{~W}$; while the extraction time and the ratio of water to raw material were set as $6 \mathrm{~min}$ and $50 \mathrm{~mL} / \mathrm{g}$, respectively), extraction time $(2,4,6,8$, and $10 \mathrm{~min}$; while the microwave power and the ratio of water to raw material were set as $400 \mathrm{~W}$ and $50 \mathrm{~mL} / \mathrm{g}$, respectively), and ratio of water to raw material $(30,40,50,60$, and $70 \mathrm{~mL} / \mathrm{g}$; while the microwave power and the extraction time were set as $400 \mathrm{~W}$ and $6 \mathrm{~min}$, respectively) on the yields of CSPs were investigated using a single-factor experimental design. Finally, the crude polysaccharides extracted from Cassia seed (CSP-M) were obtained according to the same treatment processes as described in Section 3.2.1.

A three-level Box-Behnken experimental design (BBD) was applied to further optimize the MAE conditions. The microwave power $\left(\mathrm{X}_{1}, \mathrm{~W}\right)$, ratio of water to raw material $\left(\mathrm{X}_{2}, \mathrm{~mL} / \mathrm{g}\right)$, and extraction time $\left(X_{3}, \min \right)$ were preferred for the independent variables. The variables and their levels, both the coded and actual values, are presented in Table 1. Experimental data from BBD were explained by the second-order polynomial model as follows [23]:

$$
\mathrm{Y}=A_{0}+\sum_{i=1}^{3} A_{i} X_{i}+\sum_{i=1}^{3} A_{i i} X^{2}{ }_{i}+\sum_{i=1}^{2} \sum_{j=i+1}^{3} A_{i j} X_{i} X_{j}
$$

where $\mathrm{Y}$ is the predicted response; $X_{i}$ and $X_{j}$ are different variables $(i \neq j)$; and $A_{0}, A_{i}, A_{i i}$, and $A_{i j}$ are the regression coefficients for intercept, linearity, square, and interaction, respectively.

\subsection{Characterization of Polysaccharides from Cassia Seed Extracted by HWE and MAE}

\subsubsection{Chemical Composition Analysis}

The phenol-sulfuric acid assay, m-hydroxydiphenyl assay, and Bradford's assay were utilized for the analysis of the contents of total polysaccharides, uronic acids, and proteins [53-55]. In this study, the mixture standard prepared by $50 \%$ of mannose, $30 \%$ of galactose, and $20 \%$ xylose was used to determine the contents of total polysaccharides. The contents of uronic acids and proteins in CSPs were determined with galacturonic acid and bovine serum albumin as the standards, respectively.

\subsubsection{Determination of Molecular Weights of CSP-W and CSP-M}

The absolute weight-average molecular weights $\left(M_{w}\right)$ and polydispersities $\left(M_{w} / M_{n}\right)$ of CSPs were measured by high-performance size-exclusion chromatography coupled with a multi-angle laser light scattering and refractive index detector (HPSEC-MALLS-RID), according to our previously reported 
method [40]. The Astra software (version 7.1.3, Wyatt Technology Co., Santa Barbara, CA, USA) was utilized for data acquisition and analysis. The $M_{w}$ was calculated by the Zimm method of static light scattering based on the basic light scattering equation.

\subsubsection{Determination of Intrinsic Viscosities of CSP-W and CSP-M}

The intrinsic viscosities ([ๆ]) of CSP-M and CSP-W were measured by a modified Ubbelohde viscosity method reported by our previous study [52]. The kinetic energy correlation was assumed to be negligible, and the Huggins and Kraemer equations were used to estimate the value of $[\eta]$.

\subsubsection{Determination of Constituent Monosaccharides of CSP-W and CSP-M}

Constituent monosaccharides of CSP-W and CSP-M were measured by high-performance liquid chromatography analysis according to our previously reported method [21]. Briefly, $4 \mathrm{mg}$ of each sample was hydrolyzed with $2.0 \mathrm{M}$ trifluoroacetic acid at $95^{\circ} \mathrm{C}$ for $8 \mathrm{~h}$. Then, the hydrolyzates were used for 1-phenyl-3-methyl-5-pyrazolone PMP derivatization. Meanwhile, a standard solution containing Rha, Man, GlcA, GalA, Glc, Gal, Xyl, and Ara was also derivatized by PMP. Finally, an Agilent 1260 series LC system (Agilent Technologies, Palo Alto, CA, USA) coupled with a ZORBAX Eclipse XDB-C18 column $(4.6 \times 250 \mathrm{~mm}$ i.d. $5 \mu \mathrm{m})$ and a diode array detector (DAD, Agilent Technologies, Palo Alto, CA, USA) was used to analyze the PMP derivatives.

\subsubsection{Fourier Transform Infrared (FT-IR) Spectroscopy Analysis}

A previously described method was adopted for the FT-IR spectroscopy analysis of CSPs [29]. The esterification degrees (DE) of CSPs were also determined from the FT-IR spectra according to previous methods $[2,38,41]$. The determination of DE was based on the band areas at $1780-1710 \mathrm{~cm}^{-1}$ (esterified uronic acids) and $1600-1640 \mathrm{~cm}^{-1}$ (free uronic acids). DE was calculated according to the equation as follows:

$$
\mathrm{DE}(\%)=\left(\frac{\mathrm{A}_{1740}}{\mathrm{~A}_{1740}+\mathrm{A}_{1635}}\right) \times 100
$$

\subsection{Evaluation of Antioxidant Activities of Polysaccharides from Cassia Seed Extracted by HWE and MAE}

The ABTS, DPPH, nitric oxide (NO), hydroxyl radical $(\mathrm{OH})$ scavenging activities of CSP-W and CSP-M were determined according to our previously reported methods $[30,56,57]$. These activities were measured at five different concentrations, and a logarithmic regression curve was established to calculate the $\mathrm{IC}_{50}$ values $(\mathrm{mg} / \mathrm{mL})$. Both BHT and vitamin $\mathrm{C}$ were used as positive controls.

In addition, the reducing power of CSPs was also determined according to our previously reported method [56]. The absorbance was measured at $700 \mathrm{~nm}$. The blank control contained all reagents except the sample. BHT was used as the standard and the reducing power of CSPs was expressed as absorbance at $700 \mathrm{~nm}$.

\subsection{Statistical Analysis}

All experiments were conducted in triplicate, and data were expressed in means \pm standard deviations. The obtained data were analyzed by the statistical package of the Design Expert software 8.0.5 (Stat-Ease Inc., Minneapolis, MN, USA). Statistical analysis was performed using Origin 9.0 software (OriginLab Corporation, Northampton, MA, USA). Statistical significances were carried out by an independent-sample t-test. Values of $p<0.05$ were considered as statistically significant.

\section{Conclusions}

In this study, the optimal extraction conditions of MAE for the extraction of CSPs were obtained by using the response surface methodology. Furthermore, the contents of uronic acids, molecular weights, molar ratios of constituent monosaccharides, and degrees of esterification of CSPs were significantly 
affected by the MAE and HWE methods. In addition, CSP-M exhibited strong antioxidant activities, which might be partially attributed to its low molecular weight and high content of unmethylated galacturonic acid. Results suggest that the MAE method could be an efficient technique for the extraction of CSPs with high antioxidant activity, and CSPs could be further explored as functional food ingredients.

Author Contributions: D.-T.W. and W.Q. conceived and designed the experiments; W.L. and Q.-H.H. performed the experiments; D.-T.W., W.Q., P.W., X.-R.X., Y.D., and L.Z. analyzed the data; Q.Z., and S.-Q.L. contributed reagents/materials/analysis tools; D.-T.W. and W.L. wrote the initial draft; and D.-T.W. revised the manuscript.

Funding: This work was supported by the Scientific Research Foundation of Sichuan Agricultural University (grant number 03120321) and the Scientific Research Fund Project of Science \& Technology Department of Sichuan Province (grant number 2018JY0149).

Conflicts of Interest: The authors declare that there are no conflicts of interest.

\section{References}

1. Qian, Z.J.; Ryu, B.; Kim, M.M.; Kim, S.K. Free radical and reactive oxygen species scavenging activities of the extracts from seahorse, Hippocampus kuda Bleeler. Biotechnol. Bioprocess Eng. 2008, 13, 705-715. [CrossRef]

2. Liu, C.J.; Liu, Q.; Sun, J.D.; Jiang, B.; Yan, J.F. Extraction of water-soluble polysaccharide and the antioxidant activity from Semen Cassiae. J. Food Drug Anal. 2014, 22, 492-499. [CrossRef]

3. $\quad$ Liang, X.X.; Gao, Y.Y.; Fei, W.B.; Zou, Y.F.; He, M.; Yin, L.Z.; Yuan, Z.X.; Yin, Z.Q.; Zhang, W. Chemical characterization and antioxidant activities of polysaccharides isolated from the stems of Parthenocissus tricuspidata. Int. J. Biol. Macromol. 2018, 119, 70-78. [CrossRef] [PubMed]

4. Shen, S.G.; Jia, S.R.; Wu, Y.K.; Yan, R.R.; Lin, Y.H.; Zhao, D.X.; Han, P.P. Effect of culture conditions on the physicochemical properties and antioxidant activities of polysaccharides from Nostoc flagelliforme. Carbohydr. Polym. 2018, 198, 426-433. [CrossRef] [PubMed]

5. Tang, Q.L.; Huang, G.L. Preparation and antioxidant activities of cuaurbit polysaccharide. Int. J. Biol. Macromol. 2018, 117, 362-365. [CrossRef] [PubMed]

6. Capek, P.; Machová, E.; Turjan, J. Scavenging and antioxidant activities of immunomodulating polysaccharides isolated from Salvia officinalis L. Int. J. Biol. Macromol. 2009, 44, 75-80. [CrossRef] [PubMed]

7. Chen, J.J.; Zhang, T.; Jiang, B.; Mu, W.M.; Miao, M. Characterization and antioxidant activity of Ginkgo biloba exocarp polysaccharides. Carbohydr. Polym. 2012, 87, 40-45. [CrossRef]

8. Hu, H.B.; Liang, H.P.; Li, H.M.; Yuan, R.N.; Sun, J.; Zhang, L.L.; Han, M.H.; Wu, Y. Isolation, purification, characterization and antioxidant activity of polysaccharides from the stem barks of Acanthopanax leucorrhizus. Carbohydr. Polym. 2018, 196, 359-367. [CrossRef] [PubMed]

9. Subramonian, W.; Wu, T.Y.; Chai, S.P. A comprehensive study on coagulant performance and floc characterization of natural Cassia obtusifolia seed gum in treatment of raw pulp and paper mill effluent. Ind. Crops Prod. 2014, 61, 317-324. [CrossRef]

10. Albuquerque, P.B.S.; Barros, W.; Santos, G.R.C.; Correia, M.T.S.; Mourao, P.A.S.; Teixeira, J.A.; Carneiro da Cunha, M.G. Characterization and rheological study of the galactomannan extracted from seeds of Cassia grandis. Carbohydr. Polym. 2014, 104, 127-134. [CrossRef]

11. Feng, L.; Yin, J.Y.; Nie, S.P.; Wan, Y.Q.; Xie, M.Y. Fractionation, physicochemical property and immunological activity of polysaccharides from Cassia obtusifolia. Int. J. Biol. Macromol. 2016, 91, 946-953. [CrossRef]

12. Sharmila, G.; Nikitha, V.S.; Ilaiyarasi, S.; Dhivya, K.; Rajasekar, V.; Kumar, N.M.; Muthukumaran, K.; Muthukumaran, C. Ultrasound assisted extraction of total phenolics from Cassia auriculata leaves and evaluation of its antioxidant activities. Ind. Crops Prod. 2016, 84, 13-21. [CrossRef]

13. Zhang, Z.J.; Yu, B. Total synthesis of the antiallergic naphtho- $\alpha$-pyrone tetraglucoside, cassiaside $C_{2}$, isolated from cassia seeds. J. Org. Chem. 2003, 68, 6309-6313. [CrossRef]

14. Aryal, S.; Baniya, M.K.; Danekhu, K.; Kunwar, P.; Gurung, R.; Koirala, N. Total phenolic content, flavonoid content and antioxidant potential of wild vegetables from western nepal. Plants 2019, 8, 96. [CrossRef]

15. Chan, C.L.; Gan, R.Y.; Corke, H. The phenolic composition and antioxidant capacity of soluble and bound extracts in selected dietary spices and medicinal herbs. Int. J. Food Sci. Technol. 2016, 51, 565-573. [CrossRef] 
16. Huang, Y.L.; Chow, C.J.; Tsai, Y.H. Composition, characteristics, and in-vitro physiological effects of the water-soluble polysaccharides from Cassia seed. Food Chem. 2012, 134, 1967-1972. [CrossRef]

17. Feng, L.; Yin, J.Y.; Nie, S.P.; Wan, Y.Q.; Xie, M.Y. Structure and conformation characterization of galactomannan from seeds of Cassia obtusifolia. Food Hydrocoll. 2018, 76, 67-77. [CrossRef]

18. Feng, L.; Yin, J.Y.; Nie, S.P.; Wan, Y.Q.; Xie, M.Y. Enzymatic purification and structure characterization of glucuronoxylan from water extract of Cassia obtusifolia seeds. Int. J. Biol. Macromol. 2018, 107, 1438-1446. [CrossRef]

19. Cong, Q.F.; Shang, M.S.; Dong, Q.; Liao, W.F.; Xiao, F.; Ding, K. Structure and activities of a novel heteroxylan from Cassia obtusifolia seeds and its sulfated derivative. Carbohydr. Res. 2014, 393, 43-50. [CrossRef]

20. Dong, H.M.; Zhang, Q.; Li, Y.; Li, L.; Lan, W.J.; He, J.L.; Li, H.Y.; Xiong, Y.B.; Qin, W. Extraction, characterization and antioxidant activities of polysaccharides of Chuanminshen violaceum. Int. J. Biol. Macromol. 2016, 86, 224-232. [CrossRef]

21. Han, Q.H.; Liu, W.; Li, H.Y.; He, J.L.; Guo, H.; Lin, S.; Zhao, L.; Chen, H.; Liu, Y.W.; Wu, D.T.; et al. Extraction optimization, physicochemical characteristics, and antioxidant activities of polysaccharides from kiwifruit (Actinidia chinensis Planch.). Molecules 2019, 24, 461. [CrossRef]

22. Chen, G.J.; Chen, K.W.; Zhang, R.F.; Chen, X.L.; Hu, P.; Kan, J.Q. Polysaccharides from bamboo shoots processing by-products: New insight into extraction and characterization. Food Chem. 2018, 245, 1113-1123. [CrossRef]

23. Ren, B.B.; Chen, C.; Li, C.; Fu, X.; You, L.J.; Liu, R.H. Optimization of microwave-assisted extraction of Sargassum thunbergii polysaccharides and its antioxidant and hypoglycemic activities. Carbohydr. Polym. 2017, 173, 192-201. [CrossRef]

24. Chen, Y.Y.; Xue, Y.T. Optimization of microwave assisted extraction, chemical characterization and antitumor activities of polysaccharides from porphyra haitanensis. Carbohydr. Polym. 2019, 206, 179-186. [CrossRef]

25. Sun, H.Y.; Li, C.Y.; Ni, Y.J.; Yao, L.P.; Jiang, H.W.; Ren, X.T.; Fu, Y.J.; Zhao, C.J. Ultrasonic/microwave-assisted extraction of polysaccharides from Camptotheca acuminata fruits and its antitumor activity. Carbohydr. Polym. 2019, 206, 557-564. [CrossRef] [PubMed]

26. Kazemi, M.; Khodaiyan, F.; Labbafi, M.; Hosseini, S.S.; Hojjati, M. Pistachio green hull pectin: Optimization of microwave-assisted extraction and evaluation of its physicochemical, structural and functional properties. Food Chem. 2019, 271, 663-672. [CrossRef]

27. Silva, A.D.E.; de Magalhães, W.T.; Moreira, L.M.; Rocha, M.V.P.; Bastos, A.K.P. Microwave-assisted extraction of polysaccharides from Arthrospira (Spirulina) platensis using the concept of green chemistry. Algal Res. 2018, 35, 178-184. [CrossRef]

28. Yuan, Y.; Xu, X.; Jing, C.L.; Zou, P.; Zhang, C.S.; Li, Y.Q. Microwave assisted hydrothermal extraction of polysaccharides from Ulva prolifera: Functional properties and bioactivities. Carbohydr. Polym. 2018, 181, 902-910. [CrossRef]

29. Dong, H.M.; Lin, S.; Zhang, Q.; Chen, H.; Lan, W.J.; Li, H.Y.; He, J.L.; Qin, W. Effect of extraction methods on the properties and antioxidant activities of Chuanminshen violaceum polysaccharides. Int. J. Biol. Macromol. 2016, 93, 179-185. [CrossRef]

30. Guo, H.; Yuan, Q.; Fu, Y.; Liu, W.; Su, Y.H.; Liu, H.; Wu, C.Y.; Zhao, L.; Zhang, Q.; Lin, D.R.; et al. Extraction optimization and effects of extraction methods on the chemical structures and antioxidant activities of polysaccharides from snow chrysanthemum (Coreopsis Tinctoria). Polymers 2019, 11, 215. [CrossRef]

31. Chen, Z.; Zhang, W.; Tang, X.Y.; Fan, H.J.; Xie, X.J.; Wan, Q.; Wu, X.H.; Tang, J.Z. Extraction and characterization of polysaccharides from Semen Cassiae by microwave-assisted aqueous two-phase extraction coupled with spectroscopy and HPLC. Carbohydr. Polym. 2016, 144, 263-270. [CrossRef]

32. Chen, C.; Zhang, B.; Huang, Q.; Fu, X.; Liu, R.H. Microwave-assisted extraction of polysaccharides from Moringa oleifera Lam. leaves: Characterization and hypoglycemic activity. Ind. Crop. Prod. 2017, 100, 1-11. [CrossRef]

33. Zhao, J.L.; Zhang, M.P.; Zhou, H.L. Microwave-assisted extraction, purification, partial characterization, and bioactivity of polysaccharides from Panax ginseng. Molecules 2019, 24, 1605. [CrossRef]

34. Wang, Y.G.; Xu, Y.; Ma, X.Q.; Liu, X.F.; Yang, M.J.; Fan, W.G.; Ren, H.W.; Efehi, N.; Wang, X.L.; Zhu, X.Q. Extraction, purification, characterization and antioxidant activities of polysaccharides from Zizyphus jujuba cv. Linzexiaozao. Int. J. Biol. Macromol. 2018, 118, 2138-2148. [CrossRef] 
35. Hu, Z.Y.; Wang, P.H.; Zhou, H.L.; Li, Y.P. Extraction, characterization and in vitro antioxidant activity of polysaccharides from Carex meyeriana Kunth using different methods. Int. J. Biol. Macromol. 2018, 120, 2155-2164. [CrossRef]

36. Wu, D.T.; Guo, H.; Lin, S.; Lam, S.C.; Zhao, L.; Lin, D.R.; Qin, W. Review of the structural characterization, quality evaluation, and industrial application of Lycium barbarum polysaccharides. Trends Food Sci. Technol. 2018, 79, 171-183. [CrossRef]

37. He, L.; Yan, X.T.; Liang, J.; Li, S.J.; He, H.R.; Xiong, Q.P.; Lai, X.P.; Hou, S.Z.; Huang, S. Comparison of different extraction methods for polysaccharides from Dendrobium officinale stem. Carbohydr. Polym. 2018, 198, 101-108. [CrossRef]

38. Deore, U.V.; Mahajan, H.S. Isolation and characterization of natural polysaccharide from Cassia Obtustifolia seed mucilage as film forming material for drug delivery. Int. J. Biol. Macromol. 2018, 115, 1071-1078. [CrossRef]

39. Shang, M.S.; Zhang, X.M.; Dong, Q.; Yao, J.; Liu, Q.; Ding, K. Isolation and structural characterization of the water-extractable polysaccharides from Cassia obtusifolia seeds. Carbohydr. Polym. 2012, 90, 827-832. [CrossRef]

40. Yuan, Q.; Lin, S.; Fu, Y.; Nie, X.R.; Liu, W.; Su, Y.; Han, Q.H.; Zhao, L.; Zhang, Q.; Lin, D.R.; et al. Effects of extraction methods on the physicochemical characteristics and biological activities of polysaccharides from okra (Abelmoschus esculentus). Int. J. Biol. Macromol. 2019, 127, 178-186. [CrossRef]

41. Yu, Y.; Li, Y.P.; Du, C.Y.; Mou, H.J.; Wang, P. Compositional and structural characteristics of sulfated polysaccharide from Enteromorpha prolifera. Carbohydr. Polym. 2017, 165, 221-228. [CrossRef]

42. Liang, X.X.; Gao, Y.Y.; Pan, Y.; Zou, Y.F.; He, M.; He, C.L.; Li, L.X.; Yin, Z.Q.; Lv, C. Purification, chemical characterization and antioxidant activities of polysaccharides isolated from Mycena dendrobii. Carbohydr. Polym. 2019, 203, 45-51. [CrossRef]

43. Gu, D.; Huang, L.L.; Chen, X.; Wu, Q.H.; Ding, K. Structural characterization of a galactan from Ophiopogon japonicus and anti-pancreatic cancer activity of its acetylated derivative. Int. J. Biol. Macromol. 2018, 113, 907-915. [CrossRef]

44. Fu, Y.; Yuan, Q.; Lin, S.; Liu, W.; Du, G.; Zhao, L.; Zhang, Q.; Lin, D.R.; Liu, Y.T.; Qin, W.; et al. Physicochemical characteristics and biological activities of polysaccharides from the leaves of different loquat (Eriobotrya japonica) cultivars. Int. J. Biol. Macromol. 2019, 135, 274-281. [CrossRef]

45. Hosseini, S.S.; Khodaiyan, F.; Yarmand, M.S. Optimization of microwave assisted extraction of pectin from sour orange peel and its physicochemical properties. Carbohydr. Polym. 2016, 140, 59-65. [CrossRef]

46. Wai, W.W.; Alkarkhi, A.F.M.; Easa, A.M. Effect of extraction conditions on yield and degree of esterification of durian rind pectin: An experimental design. Food Bioprod. Process. 2010, 88, 209-214. [CrossRef]

47. Thambiraj, S.R.; Phillips, M.; Koyyalamudi, S.R.; Reddy, N. Yellow lupin (Lupinus luteus L.) polysaccharides: Antioxidant, immunomodulatory and prebiotic activities and their structural characterisation. Food Chem. 2018, 267, 319-328. [CrossRef]

48. Ji, Y.H.; Liao, A.M.; Huang, J.H.; Thakur, K.; Li, X.L.; Wei, Z.J. Physicochemical and antioxidant potential of polysaccharides sequentially extracted from Amana edulis. Int. J. Biol. Macromol. 2019, 131, 453-460. [CrossRef]

49. Li, L.; Thakur, K.; Liao, B.Y.; Zhang, J.G.; Wei, Z.J. Antioxidant and antimicrobial potential of polysaccharides sequentially extracted from Polygonatum cyrtonema Hua. Int. J. Biol. Macromol. 2018, 114, 317-323. [CrossRef]

50. Zhang, Z.F.; Lv, G.Y.; He, W.Q.; Shi, L.G.; Pan, H.J.; Fan, L.F. Effects of extraction methods on the antioxidant activities of polysaccharides obtained from Flammulina velutipes. Carbohydr. Polym. 2013, 98, 1524-1531. [CrossRef]

51. Chai, Z.; Huang, W.Y.; Zhao, X.; Wu, H.; Zeng, X.X.; Li, C.Y. Preparation, characterization, antioxidant activity and protective effect against cellular oxidative stress of polysaccharide from Cynanchum auriculatum Royle ex Wight. Int. J. Biol. Macromol. 2018, 119, 1068-1076. [CrossRef]

52. Lin, S.; Guo, H.; Lu, M.; Lu, M.Y.; Gong, J.D.B.; Wang, L.; Zhang, Q.; Qin, W.; Wu, D.T. Correlations of molecular weights of $\beta$-glucans from Qingke (Tibetan hulless barley) to Their Multiple Bioactivities. Molecules 2018, 23, 1710. [CrossRef]

53. DuBois, M.; Gilles, K.A.; Hamilton, J.K.; Rebers, P.A.; Smith, F. Colorimetric method for determination of sugars and related substances. Anal. Chem. 1956, 28, 350-356. [CrossRef] 
54. Filisetti Cozzi, T.M.C.C.; Carpita, N.C. Measurement of uronic acids without interference from neutral sugars. Anal. Biochem. 1991, 197, 157-162. [CrossRef]

55. Bradford, M.M. A rapid and sensitive method for the quantitation of protein utilizing the principle of protein-dye Binding. Anal. Biochem. 1976, 72, 248-254. [CrossRef]

56. Lin, S.; Guo, H.; Gong, J.D.B.; Lu, M.; Lu, M.Y.; Wang, L.; Zhang, Q.; Qin, W.; Wu, D.T. Phenolic profiles, $\beta$-glucan contents, and antioxidant capacities of colored Qingke (Tibetan hulless barley) cultivars. J. Cereal Sci. 2018, 81, 69-75. [CrossRef]

57. Dong, Y.H.; Qi, Y.R.; Liu, M.; Song, X.L.; Zhang, C.; Jiao, X.; Wang, W.S.; Zhang, J.J.; Jia, L. Antioxidant, anti-hyperlipidemia and hepatic protection of enzyme-assisted Morehella esculenta polysaccharide. Int. J. Biol. Macromol. 2018, 120, 1490-1499. [CrossRef]

(C) 2019 by the authors. Licensee MDPI, Basel, Switzerland. This article is an open access article distributed under the terms and conditions of the Creative Commons Attribution (CC BY) license (http://creativecommons.org/licenses/by/4.0/). 